\title{
The Effects of Cultural Dimension on MIS Acceptance
}

\author{
H. Sriwindono ${ }^{1}$, S. Yahya ${ }^{2}$ \\ ${ }^{\mathbf{1}}$ Faculty of Technology Management and Technopreneurship, Universiti Teknikal Malaysia, Melaka, Malaysia \\ ${ }^{2}$ Faculty of Technology Management and Technopreneurship, Universiti Teknikal Malaysia, Melaka, Malaysia \\ (p060720002@student.utem.edu.my ; sallehyahya@utem.edu.my)
}

\begin{abstract}
In this study we explore the effects of cultural dimensions as influence factors of the Technology Acceptance Model (TAM) with the sample of academics in Indonesia. We adopted some Hofstede's cultural dimensions (power distance, individualism, and long term orientation) as influence factors to Perceive Usefulness and Perceive Ease of Use in TAM.

Research carried out by using 308 respondents, who are academics throughout Indonesia. The data obtained and analyzed using Structure Equation Modeling with PLS. Our results show, that Long Term Orientation had highest effect on Perceived Usefulness in TAM, and followed by Power Distance and Individualism on Perceived Ease of Use. These results can be taken as consideration when implementing MIS in higher learning institution in Indonesia.
\end{abstract}

Keywords - Cultural dimensions, technology acceptance

\section{INTRODUCTION}

Management Information System has rapidly proliferated, even in developing country such as Indonesia. However, though it is now global era, the MIS or ICT application acceptance research has been conducted al- most exclusively in developed countries. Also, in spite of the fact that differences in cultural dimension can affect customer behavior, most technology acceptance research has ignored the effect of culture.

Although many factors may affect an individual's acceptance of ICT application, a growing but still fragmented body of research suggests that culturally induced beliefs play an important role [6]. Numerous scholars have argued for the influence of national culture on values and behavior. A significant research has shown that individual in different country have fundamentally different value about technology. Although it is suspected that national culture affects the acceptance of technology, but research in this area is still very limited.

In this research we explore the relationship between some Hofstede's cultural dimension and ICT application acceptance by extending and enhancing technology acceptance model (TAM) [15]. This model has been developed by Straub [11] and Veiga [32]. Straub demonstrate the exogenous social presence/ information richness factor and added it as an antecedent to the TAM, while Veiga showed the Hofstede's cultural dimension which affects the technology acceptance model.

Several reasons lead us to investigate culture dimensions through Hofstede's cultural dimensions. First, the Hofstede's cultural dimensions constitute the most use and recognized dimensions as a whole or separately in studying cultural issues in organizations and management. Second, the dimensions rely on variables that are more directly link to social and organizational process. Our research Objective is to find out the culture effects on Management Information System Acceptance by academicians in Indonesia. MIS is one of ICT application usage in higher learning Institution beside its application on teaching and learning activities. To achieve these objectives, we examine the academicians' acceptance of MIS (Management Information System) especially Academic Information System in some universities in Indonesia.

\section{A. National Culture}

Culture can be defined at two levels: national level and individual level. National culture is the collective programming of the mind that distinguishes the members of one group or category of people from another. Hofs- tede had suggested that there were five work-related cultural dimensions along which countries differ. These were:

- Power Distance (PDI): the degree to which the less powerful members of organizations accept that power is distributed unequally.

- Individualism (IDV): the degree to which a society emphasizes the role of the individual.

- Masculinity (MAS): the degree to which a society emphasizes traditional masculine values (such as competitiveness, achievement, and ambition), as opposed to others (such as nurturing, helping others, and valuing quality of life)

- Uncertainty Avoidance (UAI): the degree to which people feel threatened by uncertain, unstructured situations and ambiguity

- Long-term Orientation (LTO): the extent to which people of a country show a propensity to take a long term perspective that primarily emphasizes doing things that improve the future as opposed to a short term perspective that primarily emphasize the present or the successes of the past.

Cultural values were transmitted to individual of society through institution such as family or schools; they influence the ICT acceptance by individual.

\section{B. Cultural Dimension and ICT Acceptance}

The previous researches toward relation of culture dimension to ICT acceptance are noted in Table 1. Most of them not use all of Hofstede's cultural dimensions but only one or few dimensions at a time. Some author believes that more holistic, theoretical treatment of a culture and ICT acceptance relationship is 
TABLE 1

RESEARCH ON THE INFLUENCE OF CULTURE DIMENSION ON ICT ACCEPTANCE

\begin{tabular}{ll}
\hline Power distance & In hierarchical societies, technological changes \\
& must come from top management [3]. Empirical \\
& Participative development project methodology may \\
& not be appropriate in high power distance societies \\
& such as Arab Gulf countries [16]. Theory \\
& IT can increase power among skilled IT workers \\
& giving them more equity with mana gers and \\
& motivating their acceptance [17]. Empirical \\
\hline Individualism/ & Perceived social presence of application affects \\
Collectivism & acceptance [6]. Empirical \\
& IT support for individual or cooperative work \\
& practices affects acceptance [17]. Empirical Kinship \\
& groups and work groups act as references for Arab \\
& workers in decisions about IT [3]. Empirical \\
\hline Time & Loyalty to national traditions is seen as an \\
orientation & impediment in focus groups of Arab businessmen [3]. \\
& Empirical \\
& Perceived near-term usefulness has a more significant \\
& influence on intention to use than perceived long- \\
& term usefulness in a US sample [29]. Empirical \\
& Fatalistic orientation towards the future leads to \\
& resistance to long-range IT planning in Arab Gulf \\
& countries [16]. Theory \\
& IT change makes long-term planning more important \\
and this can cause problems in cultures with short- \\
term orientation [17]. Empirical \\
\hline Four & Towards modeling the effects of national culture on \\
& IT Implementation and acceptance. The cultural \\
& dimension as a control variable of TAM [24]. \\
& Empirical. \\
&
\end{tabular}

warranted [24]. Based on this fact, we develop a more comprehensive approach to empirical test of the TAM, especially for Indonesia academics.

\section{METHODOLOGY}

Our research model included both the technology acceptance model together with variables of PU and PEOU and incorporated Hofstede's cultural dimensions of PDI, IDV, and LTO as independent variables in the model as shown on Fig 1.

The research model based on Veiga et al.'s model which integrated cultural dimension and PU and PEOU as main influencing variables of acceptance of ICT application (MIS). These variables have an effect

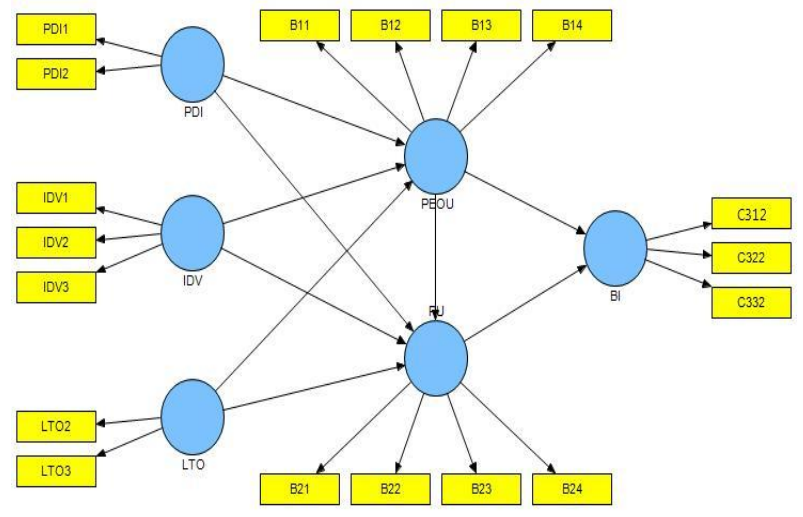

Fig. 1. The Research Model. on the intention to use, which in turn affects actual usage. Most studies use the intention to use as a dependent variable.

\section{A. Technology Acceptance Model}

Our research based on Technology Acceptance Model by Davis. Therefore we use three base hypotheses as follows:

H1 : Perceived Ease of Use has a direct positive impact on Perceived of Usefulness

H2 : Perceived Ease of Use has a direct positive impact on Behavioral Intention to use the MIS

H3 : Perceived Usefulness has a direct positive impact on Behavioral Intention to use the MIS

\section{B. Power Distance}

Power distance refers to the degree of which status in- equality is accepted as normal in given culture [18]. It conditions the extent to which someone accepts that they have less power than their superior. We posit that the Power Distance will influence the perceived of use and perceived usefulness of ICT usage. This leads to the following hypotheses:

H4 : PDI has a direct positive impact on the perceived ease of use of a system

H5 : PDI has a direct positive impact on the perceived usefulness of a system

\section{Individualistic/Collectivist}

Hofstede argued that cultures high on individualism tend to promote individual decision making over group consensus [12]. In contrast, in societies emphasizing collectivism the group becomes the primary source of an individual's identity and individuals seek approval, status and support through group affiliation. Concerns over group welfare, equality and loyalty are emphasized, as aggregate interests tend to prevail over autonomous, individualistic ones [11]. So the perceived ease of use and perceived usefulness of technology, we guess, they were influenced by individualistic/collectivist degree.

H6 : IDV has a direct positive impact on the Perceived Ease of Use of a system

H7 : IDV has a direct positive impact on the Perceived Usefulness of a system

\section{Long Term Orientation}

The dimension of long-term orientation, which was originally labeled as Confucian dynamism refers to a society's preference to be more future oriented or forward looking [14]. Cultures maintaining a long-term orientation are characterized by values emphasizing the importance of the future and perseverance. With respect to acceptance of change, members of societies with shortterm orientations are likely to be more inclined to be responsive to change if a need exists, particularly when past successes or traditions are shown to be wanted 
[13]. To make changes in society that has long-term orientation requires significant effort, because they are more likely to be conservative and reluctant to make major changes. Observations show that the acceptance of new technologies, the values associated with both long and short-term orientation is very important. In the shortterm oriented society the benefit of technology (usefulness) assessed by its benefit in solving the current tasks. This is consistent with Chau $\mathrm{s}$ finding in a US sample (a short-term-oriented culture) that near-term usefulness had a more significant influence on intention to use than perceived long term usefulness [29]. But in Indonesia, the long -term oriented can be associated with the investment, something like "saving for the future use. So that is why we arrange the following hypotheses regarding LTO:

H8: LTO has a direct positive impact on the Perceived Ease of Use of a system

H9: LTO has a direct positive impact on the Perceived Usefulness of a system

\section{RESULT}

We wished to explore the influence of cultural dimension on the model. In this research we use the Mark Srite and Elena Karahanna approach [28] which assessed cultural traits at the individual level of analysis using Hofstede's cultural dimension.

\section{a. Data Collection}

Data was collected from university academics throughout Indonesia. In total, 308 valid questioners were used in our analysis. 175 respondents were male and 133 were female. About $39 \%$ of the respondents reported use computer for more than 5 hours per day, and 48\% use computer for $2-5$ hours per day, while $14 \%$ less than 2 hours per day.

TABLE 2

DESCRIPTIVE OF RESPONDENTS CHARACTERISTIC

\begin{tabular}{llll}
\hline Measure & Value & Frequency & Percent \\
\hline Gender & Male & 175 & 56.8 \\
& Female & 133 & 43.2 \\
\hline Age & $>60$ & 3 & 1 \\
& $50-59$ & 27 & 8.8 \\
& $40-49$ & 91 & 29.5 \\
& $35-39$ & 63 & 20.5 \\
& $30-34$ & 66 & 21.4 \\
& $25-29$ & 31 & 10.1 \\
& $20-24$ & 27 & 8.8 \\
\hline Frequency of & $<2$ hours & 42 & 13.6 \\
using computer & $2-5$ hours & 147 & 47.7 \\
per day & $>5$ hours & 119 & 38.6 \\
& & & \\
\hline
\end{tabular}

TABLE 3

DESCRIPTIVE STATISTIC DATA

\begin{tabular}{|l|l|l|}
\hline Construct & mean & \multicolumn{1}{|c|}{ std } \\
\hline PEOU & 5.19 & 0.91 \\
\hline PU & 5.55 & 0.87 \\
\hline BIU & 5.66 & 0.9 \\
\hline PDI & 2.95 & 0.4 \\
\hline IDV & 4.07 & 0.69 \\
\hline LTO & 4.18 & 0.5 \\
\hline
\end{tabular}

That's means almost all of the respondent were computer literate. Detailed descriptive statistics are shown in Table 2 . The mean score and standard deviation of construct shown on Table 3 . All item had been scored using Likert Scale from 1 (Strongly disagree) to 7 (strongly agree).

\section{b. Measurements}

In the data collection step, we use questionnaire for the construct based on the previous research conducted by Davis (TAM), and the measurement of cultural dimension value were adapted from Srite and Karahanna s research. The national cultural dimension obtained from Hofstede study. We used SEM to validate the research model, and we used PLS to perform the analysis.

\section{c. Reliability and Validity}

By using PLS, we can use Confirmatory Factor Analysis to check the validity of all indicators. The indicators will be valid if their loads coefficient is above 0.5 or very significantly. The loading factor shown on Table 4 and the invalid indicators have been deleted.

The validity is shown when:

- Measurement of indicators load have a greatest value on their assigned construct rather than on the other construct on CFA, (table 4) and

- The square root of the Average Variance Construct (AVE) of each construct is larger than its correlations with other construct (table 6).

We can see from table 5, that all indicators had valid already because indicators' load have a greatest value on their assigned construct rather than on the other construct on CFA, and from table 5, we know that the square root of the Average Variance Construct (AVE) of each construct is larger than its correlations with other construct. 
TABLE 4

RESULT OF CONFIRMATORY ANALYSIS

\begin{tabular}{cccccccc}
\hline Cons. & Indic. & BI & IDV & LTO & PDI & PEOU & PU \\
\hline \multirow{5}{*}{ PEOU } & B11 & 0.259 & 0.301 & 0.204 & 0.242 & $\mathbf{0 . 8 7 5}$ & 0.677 \\
& B12 & 0.198 & 0.286 & 0.212 & 0.271 & $\mathbf{0 . 8 5 5}$ & 0.727 \\
& B13 & 0.187 & 0.275 & 0.186 & 0.329 & $\mathbf{0 . 9 1 7}$ & 0.687 \\
& B14 & 0.213 & 0.268 & 0.165 & 0.294 & $\mathbf{0 . 8 8 3}$ & 0.683 \\
\hline \multirow{5}{*}{ PU } & B21 & 0.345 & 0.308 & 0.330 & 0.334 & 0.747 & $\mathbf{0 . 9 2 1}$ \\
& B22 & 0.281 & 0.311 & 0.350 & 0.264 & 0.711 & $\mathbf{0 . 9 2 4}$ \\
& B23 & 0.295 & 0.363 & 0.331 & 0.317 & 0.746 & $\mathbf{0 . 9 3 8}$ \\
& B24 & 0.310 & 0.310 & 0.312 & 0.278 & 0.721 & $\mathbf{0 . 9 3 9}$ \\
\hline \multirow{2}{*}{ BI } & C312 & $\mathbf{0 . 9 1 4}$ & 0.205 & 0.191 & 0.220 & 0.252 & 0.348 \\
& C322 & $\mathbf{0 . 6 0 1}$ & 0.168 & 0.075 & 0.129 & 0.083 & 0.102 \\
& C332 & $\mathbf{0 . 8 8 8}$ & 0.243 & 0.158 & 0.126 & 0.200 & 0.272 \\
\hline \multirow{2}{*}{ IDV } & IDV1 & 0.176 & $\mathbf{0 . 7 7 5}$ & 0.314 & 0.384 & 0.218 & 0.184 \\
& IDV2 & 0.237 & $\mathbf{0 . 8 5 2}$ & 0.240 & 0.387 & 0.254 & 0.270 \\
& IDV3 & 0.210 & $\mathbf{0 . 9 0 4}$ & 0.571 & 0.453 & 0.321 & 0.382 \\
\hline \multirow{2}{*}{ LTO } & LTO2 & 0.164 & 0.257 & $\mathbf{0 . 9 0 6}$ & 0.264 & 0.211 & 0.349 \\
& LTO3 & 0.146 & 0.388 & $\mathbf{0 . 7 1 0}$ & 0.144 & 0.132 & 0.207 \\
\hline \multirow{2}{*}{ PDI } & PDI1 & 0.052 & 0.076 & 0.026 & $\mathbf{0 . 2 5 5}$ & 0.081 & 0.093 \\
& PDI2 & 0.221 & 0.479 & 0.279 & $\mathbf{0 . 9 6 2}$ & 0.309 & 0.306 \\
\hline
\end{tabular}

From Table 6, we can see that all value greater than 0.7 that's means all indicators are reliable to measure the latent variable.

\section{a. Hypotheses Testing}

As shown on Table 7, we can see that not all paths have a significant value. The strongest is the path between Perceived Ease of Use (PEOU) and Perceived of Usefulness (PU), where the T-value is 8.757 which greater than 2.6 as a limit of 0.01 significant level. That's mean the hypothesis H1 had been proved. This relationship was coming from Technology Acceptance Model introduced by Davis. The second strongest significant path is between Log Term Orientation (LTO) and Perceived of Usefulness (PU), with T-value 2.417, significant at 0.05 level, therefore the hypothesis $\mathrm{H} 9$ had been proven. The third strongest significant path is between Perceived of Usefulness (PU) and Behavioral Intention (BI), where the T-value is 2.010 , greater then 1.9 , that means significant at 0.05 level. Based on this facts, the hypothesis $\mathrm{H} 3$ had been proven. The fourth is relation between PDI and PEOU with the T-value 1.972, significant at 0.05 level. That's shows the hypothesis $\mathrm{H} 4$ had been proven. And at last, the relation between IDV and PEOU with T-value 1.769 is significant at 0.10 level. We can say H6 had been proven, while other hypothesis not proved, because it's T-value too small, or not significant.

The evaluation of model structure can be conducted by calculating the $\mathrm{Q}$ square value, to show how well the model generated by the data. The calculation of Qsquare based on the coefficient of determinant (RSquare) of all dependent variables (PEOU, PU and BI). The R-square value of each dependent variable listed in Table 8 . Therefore this model supported by $74 \%$ of the data. (see the formula below).

$$
\begin{aligned}
& \mathrm{Q}^{2}=1-\left(1-\mathrm{R}_{1}^{2}\right)\left(1-\mathrm{R}_{2}{ }^{2}\right)\left(1-\mathrm{R}_{3}{ }^{2}\right) \\
= & 1-(1-0.110)(1-0.147)(1-0.656) \\
= & 0.74 \text { or } 74 \%
\end{aligned}
$$

TABLE 5

CORRELATION LATENT VARIABLE AND SQUARE ROOT OF AVE

\begin{tabular}{cccccccc}
\hline & BI & IDV & LTO & PDI & PEOU & PU & $\begin{array}{l}\text { SQRT } \\
\text { (AVE) }\end{array}$ \\
\hline BI & 1.000 & & & & & 0.813 \\
IDV & 0.249 & 1.000 & & & & 0.845 \\
LTO & 0.189 & 0.368 & 1.000 & & & & 0.814 \\
PDI & 0.200 & 0.485 & 0.263 & 1.000 & & & 0.703 \\
PEOU & 0.243 & 0.320 & 0.218 & 0.322 & 1.000 & & 0.883 \\
PU & 0.331 & 0.347 & 0.355 & 0.321 & 0.786 & 1.000 & 0.931 \\
\hline
\end{tabular}

TABLE 6

COMPOSITE RELIABILITY

\begin{tabular}{cl}
\hline Cons. & Reliability \\
\hline BI & 0.850 \\
IDV & 0.882 \\
LTO & 0.795 \\
PDI & 0.794 \\
PEOU & 0.934 \\
PU & 0.963 \\
\hline
\end{tabular}

TABLE 7

HYPOTHESES TESTING RESULT

\begin{tabular}{llrll}
\hline Hypotheses & \multicolumn{1}{c}{ Path } & coef & T-Stat & \\
\hline H1 & PEOU -> PU & 0.728 & 8.757 & $(*)$ \\
H2 & PEOU -> BI & 0.046 & 0.284 & \\
H3 & PU -> BI & 0.367 & 2.010 & $(* *)$ \\
H4 & PDI ->PEOU & 0.207 & 1.972 & $(* *)$ \\
H5 & PDI -> PU & 0.022 & 0.327 & \\
H6 & IDV ->PEOU & 0.185 & 1.769 & $(* * *)$ \\
H7 & IDV -> PU & 0.038 & 0.527 & \\
H8 & LTO ->PEOU & 0.095 & 0.965 & \\
H9 & LTO -> PU & 0.177 & 2.417 & $(* *)$ \\
\hline
\end{tabular}

(*) significant at the 0.01 level

(**) significant at the 0.05 level

$(* * *)$ significant at the 0.10 level

TABLE 8

R-SQUARE

\begin{tabular}{cl}
\hline Cons. & R Square \\
\hline BI & 0.110 \\
IDV & \\
LTO & \\
PDI & \\
PEOU & 0.147 \\
PU & 0.656 \\
\hline
\end{tabular}

\section{IV.DISCUSSION}

Base on the finding of this research, the cultural dimensions which influence on the TAM model were LTO, PDI and IDV. This finding can be used as a consideration in implementing the ICT/MIS for the higher learning institution in Indonesia. The implementations were not only cover the hardware or infrastructure, but also the software and the most important thing is the strategy to assure the succeeded.

There is a good initial condition that academics had awareness in MIS usage as seen on the LTO influence. But it still need a guide and order from the top management to use MIS in universities, to increase the academics' self confident condition in using MIS is so easy. That's why the role of top management is very 
important and the ICT literacy of top management is also important. This condition can force the top management capability to develop some suitable regulation in MIS usage. So the MIS implementation can be performed successfully.

Our research had some limitation, first there is no enough research about Technology Acceptance Modeling that have proven the TAM is suitable for Indonesia condition. Second, there were only a few literatures regarding culture dimension as a control variable for TAM. Third, the sample come from all over Indonesia area, probably this situation make the mixture of culture dimension value. In table 4 the measurement items for all of the cultural dimension values showed an acceptable level of reliability and validity. However several items of cultural dimension (LTO1, PDI3) were dropped due to the low-level factor loading values for validity.

\section{CONCLUSION}

The findings of the hypotheses testing of this research were as follows.

First, the TAM model develop by Davis is not suitable for Indonesia condition, especially while the sample were obtained from academics. We can see from the disproven of Hypotheses $\mathrm{H} 2$ even the $\mathrm{H} 1$ and $\mathrm{H} 3$ can be proven. The Perceived Ease of Use did not influence the Behavioral Intention. It is proved that theory of TAM which had been developed in developed country not suit- able for developing countries especially Indonesia.

Second, we found that LTO was most influential culture dimension affecting Perceived of Usefulness in MIS acceptance. It had direct effect on Perceived of Usefulness. In a developing country like Indonesia, the LTO is very influential, especially for the highly educated people such as academics. We can see from this research that hypothesis $\mathrm{H} 9$ had been proved.

Third, Power Distance also has an effect on Perceived Ease Use. That's mean almost all of academics still need direction from the top management who had a power to forcing the policy in MIS usage. It can be understood from the proven $\mathrm{H} 4$.

Fourth, the individualistic dimension also has an effect on Perceived Ease of Use. Most of the respondents are still influenced by the others, friends or peer in using ICT. It is shown from the H6.

In the future, the researchers have to consider using the other theory such as UTAUT (Unified Theory o Acceptance and Use of Technology) which had been claimed by Venkatesh as the best theory in explaining technology acceptance [35]. It still need a proof to apply this theory in developing country especially Indonesia. Because Indonesia is very unique with its various races which are spread on various locations. We suggest to using data clustering first, based on many cultural dimensions, it will help the researcher to develop the research model easily and comparable each other. And we can also consider using the cultural dimension as moderate variable [2].

\section{REFERENCES}

[1] B.L. Kedia, and R.S. Bhagat, “ Cultural constraints on transfer of technology across nations: implications for research in international and comparative management", Academy of Management Review, 13(4), 1988, 559-571.

[2] C. Yoon"The effects of national culture values on consumer acceptance of e-commerce: Online Shoppers in China", Information \& Management 46, 2009, 294-301

[3] C.R. Hill, K.D. Loch, D.W. Straub, and K. El-Sheshai, “ A qualitative assessment of Arab culture and information technology transfer" Journal of Global Information Management, 6(3), 1998, 29-38.

[4] D.P. Ford, C.E. Connelly, D.B. Meister, "Information systems research and Hofstede s culture s consequences: an uneasy and incomplete partnership", IEEE Transactions on Engineering Management 50 (1), 2003, pp. 8-25.

[5] D. Gefen, E. Karahanna, D.W. Straub, "Trust and TAM in online shopping: an integrated model", MIS Quarterly 27 (1), 2003, pp. 51-90.

[6] D.W. Straub," The effect of culture on IT diffusion: E-mail and FAX in Japan and the U.S.", Information Systems Research, 5(1), 1994, 23-47.

[7] D. Straub, M. Keil, W. Brenner, "Testing the technology acceptance model across cultures: a three country study", Information \& Management 33 (1), 1997, pp. 1-11.

[8] E. Karahana and D. Straub , "The psychological origins of perceived usefulness and ease of use", Information \& Management 35, 1999, 237-250.

[9] F. Davis, "A technology acceptance model for empirically testing new end-user information systems: theory and results", Doctoral dissertation, Sloan School of Management, MIT. 1986.

[10] F. Davis, "Perceived usefulness, perceived ease of use, and user acceptance of information technology", MIS Quarterly, 13(3), 1989, 319-40.

[11] G. Hofstede, "Cultures and Organizations", (McGraw-Hill, London), 1991.

[12] G. Hofstede, "Culture s Consequences: Comparing Values, Behaviors, Institutions and Organizations across Nations", 2nd ed., Sage Publications, Thousand Oaks, 2001.

[13] G. Hofstede, Cultural constraints in management theories. Academy of Management Executive, 1, 1993, 81-94.

[14] G. Hofstede, and M. Bond, "The Confucius connection: from cultural roots to economic growth", Organizational Dynamics, 16(1), 1988, 4-21.

[15] G.Rose, and D.W. Straub, "Predicting general IT use: applying TAM to the Arabic world", Journal of Global Information Management, 6(3), 1998,39-46.

[16] H. Abdul-Gadar, "Information systems strategies in multinational companies in Arab Gulf Countries", International Journal of Information Management, 1997, 17(1), 3-12.

[17] H. Hasan, and G. Ditsa, "The impact of culture on the adoption of IT: an interpretive study", Journal of Global Information Management, 7(1), 1999, 5-15.

[18] I. Ajzen , "The theory of planned behavior. Organizational Behavior and Human", Decision Processes 50, 1991, 179-211.

[19] I. Ajzen and M. Fishbein ,'Understanding Attitudes and Predicting Social Behavior". Prentice-Hall Inc., Englewood Cliffs, NJ, 1980

[20] I.P.L. Png, B.C.Y. Tan, K.L. Wee, "Dimensions of national culture and corporate adoption of IT infrastructure", IEEE Transactions on Engineering Management 48 (1), 2001, pp. 3645.

[21] J.E.M. Steenkamp, F.T. Hofstede, M. Wedel, “A cross-national investigation into the individual and national cultural antecedents of consumer innovativeness", Journal of Marketing 63 (2), 1999, pp. 55-69.

[22] J.F.Veiga, J. Yanouzas, and A. Buchholtz, "Business practices: an exercise comparing Russian managers", In Proceedings of the Fifth Biennial International Manage-ment Conference of the Eastern Academy of Management, Berlin, Germany June 14-19, 1993, pp. 56-60.

[23] J.F. Veiga, J. Yanouzas, and A. Buchholtz, "Emerging cultural values among Russian managers: what will tomorrow bring? ", Business Horizons, 38(4), 1995, 20-27. 
[24] J.F. Veiga, , S. Floyd, K. Dechant, "Towards modeling the effects of national culture on IT implementation and acceptance", Journal of Information technology, 16, 2001, 145-158.

[25] K. Mathieson, "Predicting user intentions: comparing the technology acceptance model with the theory of planned behavior", Information Systems Research, 2(3), 1991,173-191.

[26] L.J. Kirsch and L.L. Cumming, "Contextual influences on selfcontrol of is professionals engaged in systems development", Accounting, Management, and Information Technologies 6(3), 1997, 191-219.

[27] M. Fishbein, and I. Azjen, "Belief, Attitude, Intention and Behavior", (Addison-Wesley, Reading, MA), 1975.

[28] M. Srite, E. Karahanna, "The role of espoused national cultural values in technology Acceptance", MIS Quarterly 30 (3), 2006, pp. 679-704.

[29] P.Y.K. Chau, "An empirical assessment of a modified technology acceptance model", Journal of Management Information Systems, 13(2), 1996, 185-204.

[30] R. Agarwal and E. Karahana, "Time flies when you re having fun: cognitive absorption and beliefs about information technology use", MIS Quarterly 24(4), 2000, 665-694.

[31] R. Agarval and J. Prassad, "The role of innovation characteristics and perceived voluntariness in the acceptance of information technologies", Decision Sciences 28(3), 1997, 557-582.

[32] S. Yeniyurt, J.D. Townsend, "Does culture explain acceptance of new products in a country? An empirical investigation", International Marketing Review 20 (4), 2003, pp. 377-396.

[33] V. Venkatesh, and F.D. Davis, "A model of the antecedents of perceived ease of use: development and test" Decision Sciences, 27(3), 1996, 451-481.

[34] V. Venkatesh, "Determinants of perceived ease of use: integrating control, intrinsic motivation, and emotion into the technology acceptance model", Information Systems Research 11, 2000, $342-365$.

[35] V. Venkatesh, M.G. Morris, G.B. Davis and F.D. Davis, "User Acceptance of Information Technology: Toward a Unified View", MIS Quarterly 27, 2003, 428-478 